\title{
In Vitro Rooting of Dendrobium nobile Orchid: Multiple Responses to Auxin Combinations
}

\author{
Abdul Aziz MIRANI ${ }^{1 *}$, Adel Ahmed ABUL-SOAD², \\ Ghulam Sarwar MARKHAND ${ }^{1}$ \\ ${ }^{1}$ Date Palm Research Institute (DPRI), Shah Abdul Latif University, Khairpur, \\ Pakistan;abdulazizmirani@gmail.com;gmarkhand@gmail.com \\ ${ }^{2}$ Horticulture Research Institute, Agricultural Research Centre, Giza, Egypt; adelaboelsoaud@gmail.com
}

\begin{abstract}
Orchids are the most adorable in flowering plants, cultivated as the cut flower and potted plants throughout the world at different occasions. For their commercial exploitation and conservation of endangered species, micropropagation has been extensively practiced, which may be affected by several factors at each step. In vitro rooting is the most important stage that may ultimately be responsible for successful transplantation of the plantlets. Auxins play a vital role for in vitro rooting. In present study NAA and IBA treatments to in vitro developed microshoots produced multiple responses. Findings show that NAA concentrations alone were better and vigorous than IBA alone in terms of number, length and root thickness. Increasing the NAA concentration from 0.1 to $3.0 \mathrm{mg} \mathrm{l}^{-1}$ proved progressive. The highest significant value in root development was obtained with NAA at $3.0 \mathrm{mg} \mathrm{l}^{-1}$. In case of IBA alone, the root number was increased by increasing its concentration up to 1.0 $\mathrm{mg}^{-1}$ but, root number decreased when the concentration of IBA was increased to $3.0 \mathrm{mg} \mathrm{l}^{-1}$. However, the combined effect of both the PGRs over root formation indicated a considerable decline in root formation as well as callus formation at microshoot bases.
\end{abstract}

Keywords: Acclimatization, callus, microshoots, micropropagation, orchids, rooting

\section{Introduction}

Orchids are considered very fascinating flowering plants due to their long lasting blooms, various shapes, forms and colours. Their resemblance to butterflies (Oncidium papilio), slipper or "moccasins" (Paphiopedilum and Cypripedium) spiders (Arachnis), moths (Phalaenopsis), or dancing ladies (Oncidium) led to their beautiful names and attraction to peoples (Adhikari and Fischer, 2012). Their modern use as the cut flower and potted plants are increased globally. Chen and Henny (2008) reported that more than 507 million foliage plantlets are annually produced worldwide including 150 million orchids.

The genus Dendrobium bears a great diversity among the sympodial orchids, containing about 1100 species, scattered from Australia to Southeast Asia and New Guinea (Pant and Thapa, 2016). Due to its attractive flowers, $D$. nobile holds a major position in cut flower industry (Bhattacharyya et al., 2014). D. nobile is one of the slow grower orchids and their propagation through conventional methods is also very slow. Moreover, they require a combination of various factors in nature for continued production. The increasing demand of orchids as the cut flower and potted plants throughout the world on various events has invited the growers to exploit plant tissue culture technology for their mass propagation to reach the market demands.

In vitro rooting and acclimatization are very important stages in micropropagation of orchids. The successful transplantation of the in vitro plantlets to ex vitro conditions during acclimatization primarily depends upon the in vitro developed roots. This may be accomplished with different culture media compositions, culture conditions and plant growth regulators (PGR) depending upon the type of species and explant. Mostly, auxins, either alone or in combination with other auxins or cytokinins, have been used in culture media for in vitro rooting of microshoots. Fukaki and Tasaka (2009) have reported that auxins stimulate lateral root initiation and development by activating quiescent pericycle cells.

In current study two different auxins namely IBA (Indole Butyric Acid) and NAA (Naphthalene Acetic Acid) were used alone and in combinations for in vitro root development of $D$. nobile orchid, and their impact on in vitro rooting and overall growth during acclimatization is discussed. 


\section{Materials and Methods}

The current study was carried out at the Biotech. Lab., DPRI, Shah Abdul Latif University, Khairpur, Sindh, Pakistan during the period from 2011 to 2012.

\section{Plantmaterial}

The plantlets with uniform growth (2-4 leaves) from the in vitro shooting medium, involved different concentrations of BA in combination with Kinetin, were selected for the current study.

\section{Mediapreparation}

The culture media used for in vitro cultures were the basal nutrient medium (MS medium) supplemented with $\mathrm{mg}^{-1}: 0.5$ pyridoxine-HCL; 0.5 nicotinic acid; 0.1 thiamine-HCL; 100.0 myo-inositol; 2.0 glycine; 400.0 glutamine; 2200.0 agar (winlap); 1400.0 gel; 30000.0 sucrose and 500.0 activated charcoal (AC). Before autoclaving the $\mathrm{pH}$ of the medium was set to $5.7 \pm 0.1$. Media was dispensed into small jars $(150 \mathrm{ml})$ in aliquots of $35 \mathrm{ml}$ per jar and was capped with polypropylene closures. Subsequently the media was autoclaved for 20 minutes at $1.11 \mathrm{~kg} / \mathrm{cm}^{2}$ and $121^{\circ} \mathrm{C}$. The concentrations and combinations of NAA and IBA used are tabulated in Table (1). All the primary roots of the selected microshoots were trimmed to the minimum length of $1-5 \mathrm{~mm}$ before starting the experiment.

\section{Evaluation of data}

Each treatment contained 5 replicates and each replicate (Jar) comprised 1 to 3 microshoots. The experiment was designed as factorial Randomized Complete Block and the data was transformed to arithmetic means prior to analysis of variance (ANOVA). The differences in means among the treatments was determined using LSD test at $5 \%$ according to Stell et al. (1980).

\section{Results and Discussion}

The rooting is the most important step in micropropagation of orchids. It has a very significant impact on plantlet survival and growth during the acclimatization stage. The central goal of the current study was to improve in vitro root development and growth of microshoots, which may have enhanced the overall growth and development of the orchid plantlets at their subsequent stages.

Table 1. Different combinations of NAA and IBA ( $\left.\mathrm{mg} \mathrm{l}^{-1}\right)$ used for rooting experiments

\begin{tabular}{ccc}
\hline Treatments & NAA & IBA \\
\hline 0 & 0.0 & 0.0 \\
1 & 0.0 & 0.1 \\
2 & 0.0 & 1.0 \\
3 & 0.0 & 3.0 \\
4 & 0.1 & 0.0 \\
5 & 1.0 & 0.0 \\
6 & 3.0 & 0.0 \\
7 & 0.1 & 0.1 \\
8 & 1.0 & 1.0 \\
9 & 3.0 & 3.0 \\
\hline
\end{tabular}

Treatment 0 is control (without any hormone).

Treatments from 7 to 9 are the combinations of both PGRs.
In vitro rooting response to $N A A$ alone

In current study NAA was found better than IBA for root formation and development. The roots formed on NAA concentrations were better and vigorous than IBA in terms of root number, length and thickness (Table 2). Increasing the NAA concentration from 0.1 to $3.0 \mathrm{mg} \mathrm{l}^{-1}$ was proved progressive for in vitro rooting. The highest significant values in root number, length and thickness were obtained with NAA at $3.0 \mathrm{mgl}^{-1}$ (Fig. 1).

It is reported that auxin treatments to in vitro microshoots strengthen the adventitious roots by inducing the internal contents of enzymes which induce cell division, elongation and differentiation of tissues (Husen and Pal, 2007; Pant et al., 2011). The results in the present study are in agreement with the findings of Parvin et al. (2009), who used two different concentrations of NAA $\left(0.1\right.$ and $\left.0.2 \mathrm{mgl}^{-1}\right)$ for in vitro growth and development of the Dendrobium orchid, found that NAA at its higher concentration $\left(0.2 \mathrm{mg} \mathrm{l}^{-1}\right)$ produced maximum roots. They suggested that increasing the concentrations of NAA might give better results. Basker and Bai (2006) have reported similar results for NAA. They observed that MS medium added with different PGRs; NAA and BA individually and in combinations showed different results for in vitro root induction of Coelogyne stricta. Among all combinations used the root number was better increased with NAA alone (1.0 and $\left.2.0 \mathrm{mgl}^{-1}\right)$.

\section{In vitro rooting response to IB $A$ alone}

In case of IBA used for rooting, root number was increased by increasing IBA concentration up to $1.0 \mathrm{mg} \mathrm{l}^{-1}$ but, root number decreased when IBA concentration was increased to $3.0 \mathrm{mg} \mathrm{l}^{-1}$ (Fig. 2). In addition, root length and thickness was also decreased with higher IBA concentrations (Table 2). Pant and Swar (2012) has reported the similar inhibitory impact of IBA on root formation at higher concentration. According to them, the increasing in concentration of IBA to $2.0 \mathrm{mg} \mathrm{l}^{-1}$ resulted in inhibition of root formation. In addition, Mohanty et al. (2012) also found parallel results during in vitro rooting of Cymbidium mastersii. Their findings show that MS medium added with $2.0 \mathrm{mg} \mathrm{l}^{-1}$ IBA produced the highest roots $(7.46 \pm 0.09)$ per plantlet as compared to the medium comprising $3.0 \mathrm{mgl}^{-1}$ IBA. Ozel et al. (2006) reported that IBA at its higher levels inhibits shoot bud formation, which may stopover root production as the auxins from the shoot apex moves to root primordial.

Moreover, according to Asghar et al. (2013), the medium containing IBA (2.0 $\left.\mathrm{mg} \mathrm{l}^{-1}\right)$ gave better roots (97.55\%) for $D$. nobile, whereas the medium containing NAA $\left(1.5 \mathrm{mg} \mathrm{l}^{-1}\right)$ produced $85.0 \%$ roots. They also reported that increasing the auxin concentration gave a gradual increase in rooting percentage, but there was a declining trend in rooting percentage with higher levels $\left(3.0 \mathrm{mg} \mathrm{l}^{-P}\right)$ as compare to the optimum levels. The highest root length $(3.47 \mathrm{~cm})$ and number (4.70) were achieved with IBA $\left(2 \mathrm{mg} \mathrm{l}^{-1}\right)$ as compared to NAA, where the highest root length $(2.25 \mathrm{~cm})$ and number (3.30) were obtained at $1.5 \mathrm{mgl}^{-1}$.

\section{In vitro rooting response to $N A A$ and IBA combinations}

Regarding the combined effect of both PGRs on root formation, there was a considerable decline in root number, thickness and length (Table 2). The treatment number 9 (T9) 
86

Table 2. Effect of different concentrations of NAA and IBA $\left(\mathrm{mgl}^{-1}\right)$ on root number, length and width of in vitro orchid plantlets

\begin{tabular}{ccccccccccccc}
\hline Treatments & $\mathrm{T} 0$ & $\mathrm{~T} 1$ & $\mathrm{~T} 2$ & $\mathrm{~T} 3$ & $\mathrm{~T} 4$ & $\mathrm{~T} 5$ & $\mathrm{~T} 6$ & $\mathrm{~T} 7$ & $\mathrm{~T} 8$ & T9 & $\begin{array}{c}\text { LSD at } \\
0.05\end{array}$ \\
\hline NAA/IBA $\left(\mathrm{mgl}^{-1}\right)$ & $0.0 / 0.0$ & $0.0 / 0.1$ & $0.0 / 1.0$ & $0.0 / 3.0$ & $0.1 / 0.0$ & $1.0 / 0.0$ & $3.0 / 0.0$ & $0.1 / 0.1$ & $1.0 / 1.0$ & $3.0 / 3.0$ \\
Root number & $6.1 \mathrm{e}$ & $7.9 \mathrm{bc}$ & $8.1 \mathrm{~b}$ & $7.1 \mathrm{~cd}$ & $7.2 \mathrm{bcd}$ & $9.8 \mathrm{a}$ & $12.0 \mathrm{a}$ & $6.5 \mathrm{de}$ & $5.8 \mathrm{e}$ & $4.6 \mathrm{f}$ & $0.000^{* * *}$ \\
Root length $(\mathrm{cm})$ & $3.8 \mathrm{~d}$ & $4.6 \mathrm{c}$ & $4.7 \mathrm{bc}$ & $4.6 \mathrm{~cd}$ & $4.6 \mathrm{c}$ & $5.3 \mathrm{ab}$ & $5.4 \mathrm{a}$ & $4.4 \mathrm{c}$ & $4.0 \mathrm{~cd}$ & $3.7 \mathrm{~d}$ & $0.000^{* * *}$ \\
Root thickness $(\mathrm{cm})$ & $2.0 \mathrm{de}$ & $2.0 \mathrm{~cd}$ & $2.1 \mathrm{~cd}$ & $2.0 \mathrm{de}$ & $2.2 \mathrm{bc}$ & $2.4 \mathrm{~b}$ & $2.7 \mathrm{a}$ & $2.0 \mathrm{de}$ & $1.9 \mathrm{de}$ & $1.8 \mathrm{e}$ & $0.000^{* * *}$ \\
\hline
\end{tabular}
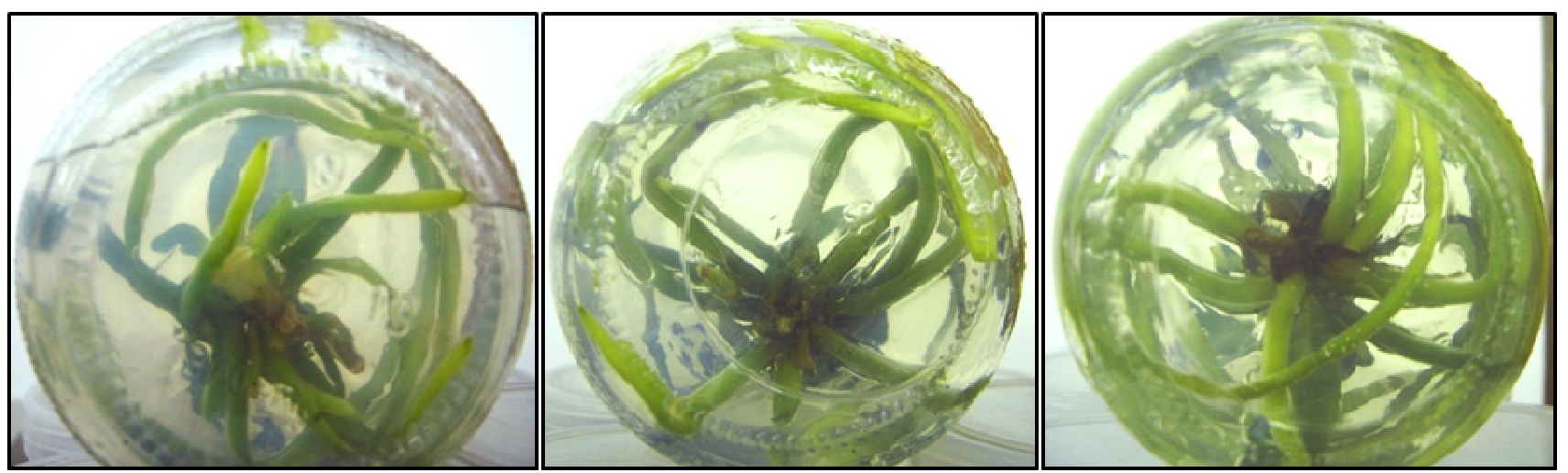

Fig. 1. In vitro better root formation of orchid plantlets on $3.0 \mathrm{mg} \mathrm{l}^{-1} \mathrm{NAA}$ (right jar) compared to 0.1 and $1.0 \mathrm{mg} \mathrm{l}^{-1} \mathrm{NAA}$ (left to right two jar)

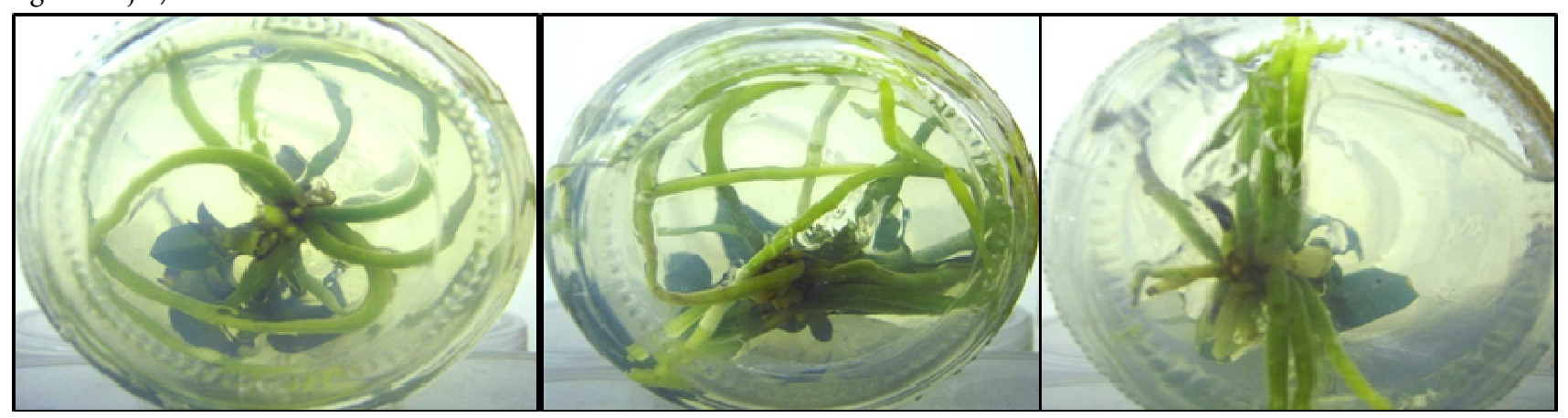

Fig. 2. In vitro better root formation of orchid plantlets on 0.1 and $1.0 \mathrm{mg} \mathrm{l}^{-1} \mathrm{IBA}$ (from left to right two jars), compared to 3.0 $\mathrm{mg} \mathrm{l}^{-1}$ IBA (right jar)

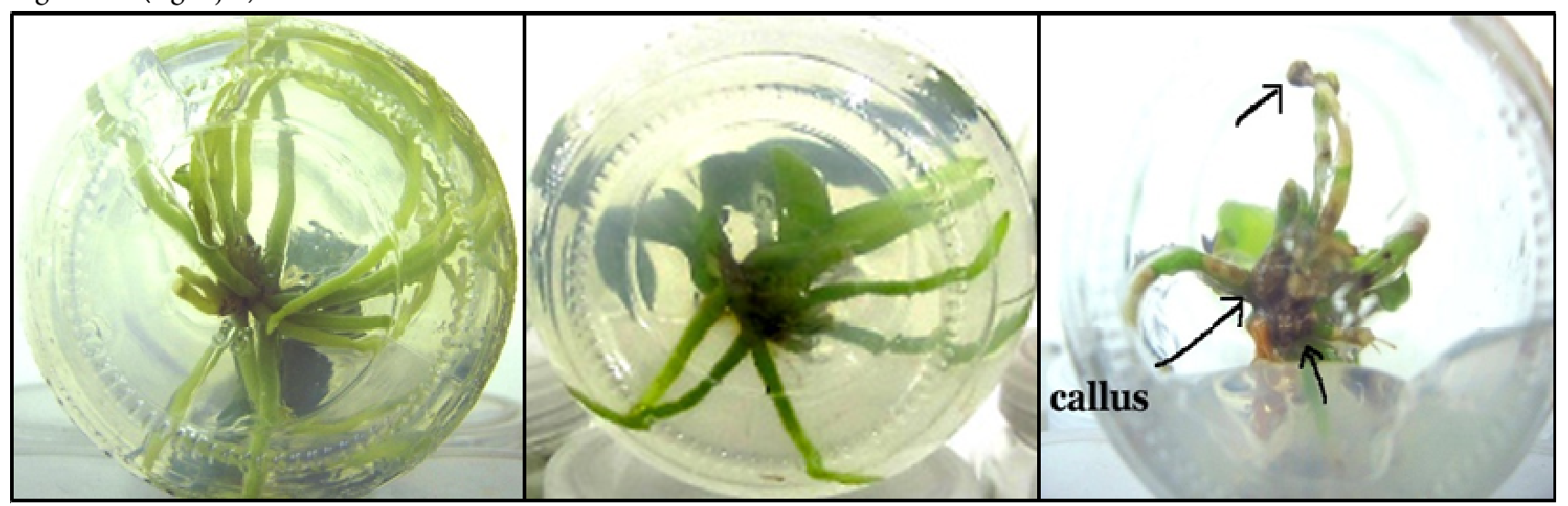

Fig. 3. In vitro inhibitory impact of increasing NAA and IBA from $0.1 / 0.1$ and $1.0 / 1.0 \mathrm{mg} \mathrm{l}^{-1}$ to $3.0 / 3.0 \mathrm{mg} \mathrm{l}^{l^{-1}}$, jars from left to right

containing NAA $\left(3.0 \mathrm{mgl}^{-1}\right)$ in combination with IBA $(3.0 \mathrm{mg}$ $\left.\mathrm{I}^{-1}\right)$ showed the poorest rates in root formation. Moreover, in T9, there was callus formation at microshoot base with much reduced root number and length (Fig. 3). The plant growth regulator IBA is considered as a physiologically more active auxin than NAA (Liu et al., 2002). In present study, IBA at its higher concentration in combination with NAA gave less number of roots than NAA and IBA alone, probably due to the inhibitory effect produced by IBA and NAA accumulations at higher concentration.

\section{Impact of $N A A$ and IBA during ex vitro acclimatization}

The results obtained during acclimatization were similar to the in vitro results. The treatment containing $3.0 \mathrm{mg} \mathrm{l}^{-1} \mathrm{NAA}$ 


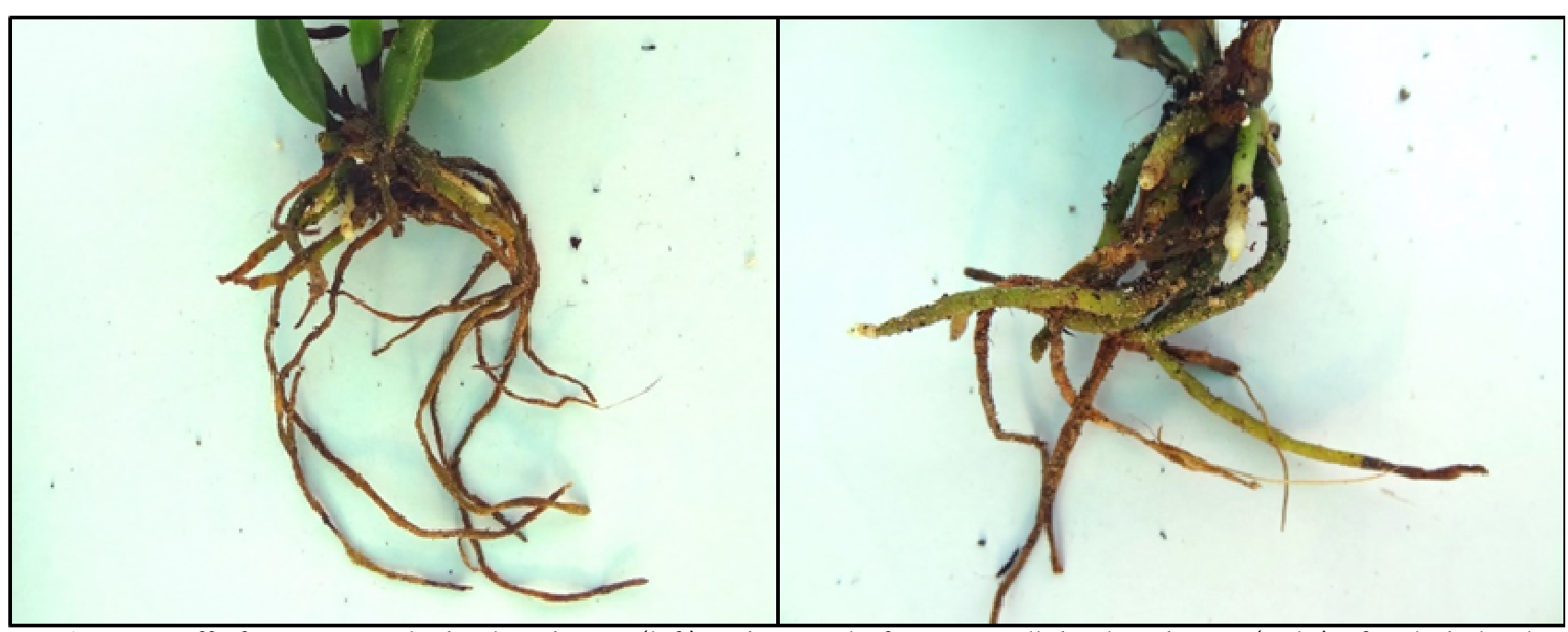

Fig. 4. Dying-off of in vitro poorly developed roots (left) and survival of in vitro well developed roots (right) of orchid plantlets during acclimatization stage in net house

Table 3. Effect of NAA and IBA $\left(\mathrm{mgl}^{-1}\right)$ on different growth parameter of orchid plantlets under net house conditions

\begin{tabular}{|c|c|c|c|c|c|c|c|c|c|c|c|}
\hline Treatments & T0 & $\mathrm{T} 1$ & $\mathrm{~T} 2$ & T3 & $\mathrm{T} 4$ & T5 & T6 & $\mathrm{T} 7$ & T8 & T9 & LSD at \\
\hline $\mathrm{NAA} / \mathrm{IBA}\left(\mathrm{mg} \mathrm{l}^{-1}\right)$ & $0.0 / 0.0$ & $0.0 / 0.1$ & $0.0 / 1.0$ & $0.0 / 3.0$ & $0.1 / 0.0$ & $1.0 / 0.0$ & $3.0 / 0.0$ & $0.1 / 0.1$ & $1.0 / 1.0$ & $3.0 / 3.0$ & 0.05 \\
\hline Shoot number & $3.15 b c$ & $3.17 \mathrm{bc}$ & $3.17 \mathrm{bc}$ & $3.27 \mathrm{~b}$ & $3.33 \mathrm{~b}$ & $3.50 \mathrm{ab}$ & $3.72 \mathrm{a}$ & $3.40 \mathrm{ab}$ & $3.27 \mathrm{~b}$ & $2.90 \mathrm{c}$ & $0.004^{* *}$ \\
\hline Leaf number & $4.40 \mathrm{cde}$ & $5.25 \mathrm{abc}$ & $5.49 a$ & $5.30 \mathrm{ab}$ & 4.83abcd & $4.50 \mathrm{bcde}$ & $4.17 \mathrm{de}$ & $4.95 \mathrm{abcd}$ & $4.67 \mathrm{abcd}$ & $3.75 \mathrm{e}$ & $0.003^{* *}$ \\
\hline Leaf length $(\mathrm{cm})$ & $5.24 \mathrm{~d}$ & $6.23 c$ & $6.42 \mathrm{bc}$ & $6.01 \mathrm{c}$ & $6.46 \mathrm{bc}$ & $6.81 \mathrm{ab}$ & $7.13 \mathrm{a}$ & $6.00 \mathrm{c}$ & $4.83 \mathrm{de}$ & $4.48 \mathrm{e}$ & $0.000^{* * *}$ \\
\hline Leaf width $(\mathrm{cm})$ & $2.08 \mathrm{cde}$ & 2.10cde & $2.19 \mathrm{bcde}$ & $2.29 \mathrm{bcd}$ & $2.40 b c$ & $2.45 \mathrm{~b}$ & $2.83 \mathrm{a}$ & $2.01 \mathrm{def}$ & $1.90 \mathrm{ef}$ & $1.74 \mathrm{f}$ & $0.000^{* * *}$ \\
\hline
\end{tabular}

Means followed by the same letter $(s)$ in each row are insignificantly different at $5 \%$ level

followed by $1.0 \mathrm{mg} \mathrm{l}^{-1} \mathrm{NAA}$, was better among all the treatments in terms of increase in shoot number, length and width.

The data show in the Table 3 that the maximum rate of shoot formation was found on $\mathrm{T} 6\left(3.0 \mathrm{mgl}^{-1} \mathrm{NAA}\right)$ where the root formation, length and thickness was also better during in vitro phase (Fig. 1). Whereas, the lowest rate in shoot formation was found on T9 $\left(3.0 \mathrm{mg} \mathrm{l}^{-1} \mathrm{NAA}\right.$ and $3.0 \mathrm{mg} \mathrm{l}^{-1}$ IBA). Similar results were obtained in respect to leaf length. The highest rate of leaf length was recorded on the same treatment (T6). The lowest rate in leaf length was found on T9, where the inhibitory impact of NAA and IBA combinations were observed during in vitro phase. The leaf width was also statistically significant on $\mathrm{T} 6$ followed by the T5. The lowest value among all treatments was again found on T9.

In general, the plantlets grown in NAA treatments were found better during ex vitro phase as compared to the plantlets grown in treatments containing IBA alone or in combination. The rooting quality of in vitro grown orchid plantlets was the most important factor that increased the overall growth in $e x$ vitro phase. During ex vitro phase, it was found that the plantlets with well-developed in vitro roots, formed with NAA treatments ( 3.0 and $\left.1.0 \mathrm{mgl}^{-1}\right)$, were better adaptable to ex vitro conditions, as compared to in vitro poorly developed roots, formed with IBA alone or in combination (Fig. 4). It is reported by Hegazy et al. (2006) that the optimum growth rate of ex vitro plantlets did not occur until new roots and leaves developed in the green house. In the present study it was observed that the inferior quality of root led to extend the required time for an early growth of ex vitro plantlets from 2 to 3 months. During which the plantlets may be exposed to fungal infection under the humid conditions at early phase of acclimatization (Abul-Soad and Jatoi, 2014).

\section{Conclusions}

The plant growth hormones NAA and IBA are very vital for in vitro plantlets rooting. Generally, NAA concentrations alone were better and vigorous than IBA alone. The highest significant value in root development was obtained with NAA alone. However, In case of IBA alone, root number decreased when the concentration of IBA was increased to $3.0 \mathrm{mg} \mathrm{l}^{-1}$. The combined effect of both the PGRs over root formation indicated a considerable decline in root formation as well as callus formation at microshoot bases.

\section{References}

Abul-Soad AA, Jatoi MA (2014). Factors affecting in vitro rooting of Date Palm (Phoenix dactylifera L). Pakistan Journal of Agricultural Sciences 51(2):467-474.

Adhikari YP, Fischer A (2012). Distribution pattern of the epiphytic orchid Rhynchostylis retusa under strong human influence in Kathmandu valley, Nepal. Botanica Orientalis: Journal of PlantScience 8:90-99.

Asghar S, Ahmad T, Hafiz IA, Yaseen M (2013). In vitro propagation of orchid (Dendrobium nobile) var. Emma white. African Journal of Biotechnology 10(16):3097-3103. 
88

Basker S, Bai VN (2006). De Segmentos De Pseudobulbos. Tropical and Subtropical Agroecosystems 6:31-35.

Bhattacharyya P, Kumaria S, Diengdoh R, Tandon P (2014). Genetic stability and phytochemical analysis of the in vitro regenerated plants of Dendrobium nobile Lindl, an endangered medicinal orchid. Meta Gene 2:489-504.

Chen J, Henny R (2008). Role of micropropagation in the development of ornamental foliage plant industry. Floriculture, Ornamental and Plant Biotechnology 5:206-218.

Fukaki H, Tasaka M (2009). Hormone interactions during lateral root formation. Plant Molecular Biology 69(4):437-449.

Hegazy A, Kansowa O, Abul-Soad A, Nasr M(2006). Growing behaviours of ex vitro date palm plants after acclimatization. Paper presented at the second international conference of genetic engineering and its applications. SharmEl-Sheik City, South Sinai,Egypt.

Husen A, Pal M (2007). Metabolic changes during adventitious root primordium development in Tectona grandis Linn. f. (teak) cuttings as affected by age of donor plants and auxin (IBA and NAA) treatment. NewForests 33(3):309-323.

Liu C, Zhu J, Liu Z, Li L, Pan R, Jin L (2002). Exogenous auxin effects on growth and phenotype of normal and hairy roots of Pueraria lobata (Willd) Ohwi. Plant Growth Regulation 38(1):37-43.
Mohanty P, Paul S, Das M C, Kumaria S, Tandon P (2012). A simple and efficient protocol for the mass propagation of Cymbidium mastersii: an ornamental orchid of Northeast India. AoB plants, 2012, pls023.

Ozel C A, Khawar K M, Mirici S, Arslan O, Sebahattin O (2006). Induction of ex vitro adventitious roots on soft wood cuttings of Centaurea tchihatcheffi Fisch et. Mey using indole-3-butyric acid and $\alpha$ naphthalene acetic acid. International Journal of Agriculture and Biology 8(1):66-69.

Pant B, ShresthaS, Pradhan S (2011). In vitro seed germination and seedling development of Phaius tancarvilleae (L'Her.) Blume. Scientific World 9(9):50-52.

Pant B, Swar S (2012). Micropropagation of Cymbidium iridioides. Nepal Journal ofScience and Technology 12:91-96.

Pant B, Thapa D (2016). In vitro mass propagation of an epiphytic orchid, Dendrobium primulinum Lindl. through shoot tip culture. African Journal of Biotechnology 11(42):9970-9974.

Parvin M, Haque M, Akhter F, Moniruzzaman M, Khaldun A (2009). Effect of different levels of NAA on in vitro growth and development of shoots of Dendrobium orchid. Bangladesh Journal of Agricultural Research 34(3):411-416.

Stell R, Torrie J, Dickey D (1980). Principles and procedures of statistics: a biometrical approach. New York: MacGraw-Hill. 